\title{
Mental Toughness dan Competitive Anxiety Pada Atlet Karate UNM
}

\author{
Aidil Ikhram ${ }^{1}$ \\ Fakultas Psikologi, Program Studi Psikologi, Universitas Negeri Makassar \\ aidilikhram97@gmail.com \\ Muh. Jufri ${ }^{2}$ \\ Fakultas Psikologi, Program Studi Psikologi, Universitas Negeri Makassar \\ m.jufri@unm.ac.id \\ Ahmad Ridfah ${ }^{3}$ \\ Fakultas Psikologi, Program Studi Psikologi, Universitas Negeri Makassar \\ ahmad.ridfah@unm.ac.id
}

\begin{abstract}
Athletes who experience competitive anxiety cannot provide optimal performance in competing, so they must have a strong mental or mental toughness in order to face any situation. This study aims to see whether there is an effect of mental toughness on competitive anxiety in UNM karate athletes. The hypothesis in this study is that there is a negative effect of mental toughness on competitive anxiety of UNM karate athletes. The method used in this research is quantitative research methods. The research subjects consisted of 53 karate athletes. The measuring instruments used were mental toughness scale and competitive anxiety scale, which were analyzed using simple linear regression analysis techniques. The results showed that there was a positive effect between mental toughness and competitive anxiety in Universitas Negeri Makassar karate athletes $(R=0.729 ; p=0.000)$. This study obtained different results from the previous literature. Researchers consider that there are other factors, namely competing experience that disturbs mental toughness of athletes so that it does not negatively affect competitive anxiety.
\end{abstract}

Keywords: athletes, competitive anxiety, mental toughness.

\begin{abstract}
Abstrak
Atlet yang mengalami competitive anxiety tidak dapat memberikan performa yang optimal dalam bertanding, sehingga harus memiliki mental yang kuat atau mental toughness agar dapat menghadapi segala keadaan. Penelitian ini bertujuan untuk melihat apakah terdapat pengaruh mental toughness terhadap competitive anxiety pada atlet karate UNM. Hipotesis dalam penelitian ini yaitu terdapat pengaruh negatif mental toughness terhadap competitive anxiety atlet karate UNM. Metode yang digunakan dalam penelitian ini adalah metode penelitian kuantitatif. Subjek penelitian terdiri dari 53 atlet karate. Alat ukur yang digunakan yaitu skala mental toughness dan skala competitive anxiety, yang dianalisis menggunakan teknik analisis regresi linear sederhana. Hasil penelitian menunjukkan bahwa terdapat pengaruh positif antara mental toughness terhadap competitive anxiety pada atlet karate Universitas Negeri Makasar $(R=0,729 ; \mathrm{p}=0,000)$. Penelitian ini mendapatkan hasil yang berbeda dari literatur sebelumnya. Peneliti menganggap adanya faktor lain, yaitu pengalaman bertanding yang mengganggu mental toughness atlet sehingga tidak dapat berpengaruh negatif terhadap competitive anxiety.
\end{abstract}

Kata kunci: atlet, competitive anxiety, mental toughness. 


\section{PENDAHULUAN}

Kesehatan adalah kebutuhan terpenting bagi individu. Demi mendapatkan tubuh yang sehat, individu seringkali menempuh banyak cara, seperti mengonsumsi makanan bergizi dan berolahraga secara teratur. Nugroho (2012) mengemukakan bahwa individu yang berolahraga secara teratur dapat meningkatkan kesehatannya sebesar 71,27\%, meningkatkan kebutuhan akan rekreasi sebesar 5,02\%, berprestasi sebesar 6,85\%, dan kebutuhan lainnya sebesar $16,86 \%$.Salah satu olahraga individu yang sangat diminati yaitu karate. Karate merupakan jenis olahraga bela diri dengan menggunakan tangan kosong tanpa bantuan senjata. Individu demi mencapai prestasi dalam bidang olahraga akan bergabung dalam sebuah kelompok cabang olahraga yang disebut atlet, salah satunya atlet karate. Faktor yang mempengaruhi dalam pencapaian atlet yaitu faktor fisik, psikologis, dan teknik. Permasalahan yang cenderung dialami oleh atlet terkait dengan mental yaitu kecemasan.

Kecemasan adalah reaksi emosional negatif yang timbul dalam bidang olahraga pada saat pertandingan atlet ketika dirinya merasa terancam. Kecemasan biasanya timbul karena atlet banyak memikirkan akibat dari kekalahannya. Algani, Yuniardi dan Masturah (2018) mengemukakan bahwa kecemasan bertanding merupakan perasaan gelisah, tidak tenang, khawatir, dan menganggap kompetisi sebagai sesuatu berbahaya yang disertai dengan terjadinya perubahan fisiologis seperti pernapasan menjadi cepat, tekanan darah meningkat, keram pada perut, detak jantung meningkat, dan wajah memerah. Algani, dkk. (2018) mengemukakan bahwa competitive anxiety adalah respon negatif yang ditampilkan oleh atlet ketika harga diri mereka terancam, yang disebabkan karena timbulnya anggapan bahwa pertandingan merupakan tantangan yang berat, jika dibandingkan dengan kemampuan yang mereka miliki, sehingga menimbulkan efek pada perilaku bertanding.

Peneliti mendapatkan data awal sebanyak 30 subjek pada Biro Kegiatan Mahasiswa Fakultas (BKMF) Karate di Fakultas Ilmu Keolahragaan UNM dengan menggunakan skala kecemasan bertanding yang dikembangkan oleh Algani, dkk. (2018) dari dari Smith, Smoll, dan Schutz (1990) yaitu Sport Anxiety Scale (SAS). Hasil tersebut menunjukkan bahwa terdapat 12 atlet dalam kategori tinggi yaitu 40\%, 9 atlet dalam kategori sedang yaitu 30\%, 8 atlet dalam kategori rendah yaitu 26,667\%, dan 1 atlet dalam kategori sangat rendah yaitu $3,333 \%$. Hasil data awal yang diperoleh dapat disimpulkan bahwa tingkat kecemasan atlet di BKMF Fakultas Ilmu Keolahragaan UNM, khususnya cabang karate cenderung tinggi.

Atlet mampu mengurangi kecemasan pada saat bertanding yaitu dengan memperkuat mental. Oleh karena itu, atlet harus memiliki kualitas mental yang baik agar dapat mengatasi 
gangguan psikologis seperti kecemasan yang dapat memberikan efek negatif pada performa atlet dalam bertanding. Untuk mencapai kualitas mental yang optimal, maka atlet harus memiliki mental toughness yang baik. Gucciardi, Gordon, dan Dimmock (2008) mengemukakan bahwa mental toughness merupakan emosi, perilaku, sikap, dan kumpulan nilai yang membuat atlet dapat melalui berbagai hambatan, tekanan, dan kesusahan yang dialami. Raynadi, Rachmah, dan Akbar (2017) mengemukakan bahwa mental toughness memiliki pengaruh terhadap competitive anxiety karena ketika atlet memiliki kesadaran bahwa aspek mental memiliki peranan penting dalam pencapaian atlet pada suatu pertandingan, kemudian mereka dapat bertahan melalui berbagai hambatan, tekanan, atau kesusahan yang dialami, maka kecemasan bertanding yang mereka alami menjadi menurun. Algani, dkk. (2018) melaporkan bahwa atlet dengan mental toughness yang tinggi akan menunjukkan competitive anxiety yang rendah bagi atlet bola voli, begitupun sebaliknya.

Berdasarkan pemaparan di atas, hipotesis yang diajukan dalam penelitian ini adalah terdapat pengaruh negatif mental toughness terhadap competitive anxiety, mental toughness yang tinggi dapat membuat atlet menjadi tetap rileks dan menurunkan competitive anxiety pada atlet karate BKMF Fakultas Ilmu Keolahragaan Universitas Negeri Makassar.

\section{METODE}

Penelitian ini menggunakan pendekatan kuantitatif. Populasi dalam penelitian ini merupakan atlet karate yang masuk dalam Biro Kegiatan Mahasiswa Fakultas Karate Fakultas Ilmu Keolahragaan Universitas Negeri Makassar (BKMF Karate FIK UNM) dengan jumlah 53 orang. Azwar (2010) mengemukakan bahwa populasi penelitian adalah kelompok subjek yang hendak dikenai generalisasi dari hasil penelitian. Teknik pengambilan sampel menggunakan total sampling. Sugiyono (2013) mengemukakan bahwa total sampel adalah teknik pengambilan sampel dari semua anggota populasi yang diterapkan untuk mengambil sampel penelitian. Hal ini dilakukan dengan melibatkan sampel dari seluruh anggota populasi yang bertujuan untuk dilibatkan sebagai sampel penelitian.

Alat ukur yang digunakan yaitu skala mental toughness dan competitive anxiety model Likert dalam proses pengumpulan data. Skala mental toughness adalah skala dari Algani (2018) yang diadaptasi oleh peneliti dan memiliki aspek-aspek, yaitu sport awareness, though attitude, thrive though challenge, dan desire success. Total item skala yang telah diadaptasi adalah 23 item yang terdiri atas 6 item thrive though challenge, 6 item sport awareness, 5 item though attitude, dan 6 item desire success. Berdasarkan penilaian ketiga professional judgment 
diperoleh koefisien validasi isi yang terdiri 23 item dimulai dari 0,75-1. Daya diskriminasi item berdasarkan hasil uji coba diperoleh 4 item yang gugur dari 23 item dan hanya 19 item yang dapat digunakan dengan koefisien korelasi 0,337-0,626. Reliabilitas berdasarkan hasil uji coba kepada 80 atlet diperoleh nilai Cronbach Alpha =0,849. Semakin tinggi nilai Cronbach Alpha, maka semakin menunjukkan tingginay nilai reliabilitas.

Skala competitive anxiety adalah skala dari Algani (2018) yang diadaptasi oleh peneliti dan memiliki aspek-aspek, yaitu cognitive, affective, somatic, dan motoric. Total item skala yang telah diadaptasi adalah 20 item yang terdiri atas 2 item cognitive, 5 item affective, 5 item somatic, dan 8 item motoric. Berdasarkan penilaian ketiga professional judgment diperoleh koefisien validasi isi yang terdiri 20 item dimulai dari 0,75-1,00. Daya diskriminasi item berdasarkan hasil uji coba diperoleh 2 item yang gugur dari 20 item dan hanya 18 item yang dapat digunakan dengan koefisien korelasi 0,332-0,657. Reliabilitas berdasarkan hasil uji coba kepada 80 atlet diperoleh nilai Cronbach Alpha $=0,853$. Semakin tinggi nilai Cronbach Alpha, maka semakin menunjukkan tingginay nilai reliabilitas.

Analisis data yang diterapkan yaitu deskriptif dan hipotesis. Statistik deskriptif bertujuan untuk mendapatkan nilai standar deviasi, rata-rata, skor minimum, skor maksimum, dan distribusi frekuensi. Hasil tersebut di konversikan menjadi tiga kategori yaitu rendah, sedang, dan tinggi. Sedangkan untuk menjawab hipotesis penelitian diuji menggunakan teknik analisis regresi linier sederhana. Uji regresi linier sederhana dan korelasi product moment digunakan untuk melihat pengaruh antara dua variabel.

\section{HASIL DAN PEMBAHASAN}

\section{Hasil}

Tabel 1.

Deskripsi Subjek Penelitian

\begin{tabular}{lll}
\hline Karakteristik Subjek & Frekuensi & Persentase (\%) \\
\hline Jenis Kelamin & & \\
Laki-laki & 31 & $58,491 \%$ \\
Perempuan & 22 & $41,509 \%$ \\
Usia & & \\
17 Tahun & 3 & $5,660 \%$ \\
18 Tahun & 10 & $18,868 \%$ \\
19 Tahun & 12 & $22,642 \%$ \\
20 Tahun & 19 & $35,849 \%$ \\
21 Tahun & 4 & $7,547 \%$ \\
22 Tahun & 5 & $9,434 \%$ \\
Jurusan & & \\
\hline
\end{tabular}




\begin{tabular}{llc}
\hline PJKR & 22 & $41,509 \%$ \\
PKO & 22 & $41,509 \%$ \\
IKOR & 9 & $16,981 \%$ \\
Pengalaman Bertanding & & \\
$<3$ kali bertanding & 44 & $83,03 \%$ \\
$>3$ kali bertanding & 13 & $16,98 \%$ \\
\hline Keterangan. PJKR = Pendidikan Jasmani Kesehatan dan Rekreasi; & PKO= Pendidikan Keperatih
\end{tabular}

Keterangan. $\quad$ PJKR $=$ Pendidikan Jasmani Kesehatan dan Rekreasi; $\quad$ PKO = Pendidikan Kepelatihan

Olahraga; IKOR = Ilmu Keolahragaan.

Pada tabel 1 menunjukkan bahwa mayoritas subjek yang digunakan dalam penelitian ini yaitu laki-laki $(58,491 \%)$, yang berusia 20 tahun $(35,849 \%)$, berasal dari jurusan Pendidikan Kepelatihan Olahraga dan Pendidikan Jasmani Kesehatan dan Rekreasi yang menunjukkan masing-masing nilai persentase sebesar $41,509 \%$, dengan pengalaman bertanding $<3$ kali bertanding $(83,03 \%)$.

Tabel 2.

Rerata Tabel Deskriptif

\begin{tabular}{lllll}
\hline \multirow{2}{*}{ Variabel } & \multicolumn{3}{l}{ Hipotetik } & \\
\cline { 2 - 5 } & Min & Max & Mean & SD \\
\hline Mental toughness & 54 & 60 & 57 & 12 \\
Competitive anxiety & 51 & 58 & 55 & 12 \\
\hline
\end{tabular}

Pada tabel 2 menunjukkan bahwa pada skala mental toughness mendapatkan skor terendah adalah 54 dan tertinggi adalah 60, dengan nilai mean deskriptif sebesar 57 dan nilai SD deskriptif sebesar 12. Sedangkan pada skala competitive anxiety mendapatkan skor terendah adalah 51 dan tertinggi adalah 58, dengan nilai mean deskriptif sebesar 55 dan nilai SD sebesar 12.

Tabel 3.

Kategorisasi dan Interpretasi Skor Mental Toughness

\begin{tabular}{lllll}
\hline Rumus & Interval & $f$ & $\%$ & Kategori \\
\hline $\mathrm{x}<(\mu-1,0 \sigma)$ & $\mathrm{x}<45$ & 0 & $0 \%$ & Rendah \\
$(\mu-1,0 \sigma) \leq \mathrm{x}<(\mu+1,0 \sigma)$ & $46 \leq \mathrm{x}<69$ & 53 & $100 \%$ & Sedang \\
$(\mu+1,0 \sigma) \leq \mathrm{x}$ & $70 \leq \mathrm{x}$ & 0 & $0 \%$ & Tinggi \\
\hline Total & & 53 & $100 \%$ & \\
\hline Ket & & $53 \%$
\end{tabular}

Keterangan. $\mathrm{X}=$ Nilai total subjek; $\mu=$ Nilai rata-rata subjek; $\sigma=$ Nilai standar deviasi subjek; $f=$ Frekuensi. 
Data pada tabel 3 mengonfirmasi bahwa tidak terdapat subjek yang memiliki mental toughness rendah, 53 (100\%) subjek yang memiliki tingkat mental toughness sedang, dan 0 $(0 \%)$ subjek memiliki tingkat mental toughness tinggi.

Tabel 4.

Kategorisasi dan Interpretasi Skor Competitive Anxiety

\begin{tabular}{lllll}
\hline Rumus & Interval & $f$ & $\%$ & Kategori \\
\hline $\mathrm{x}<(\mu-1,0 \sigma)$ & $\mathrm{x}<43$ & 0 & $0 \%$ & Rendah \\
$(\mu-1,0 \sigma) \leq \mathrm{x}<(\mu+1,0 \sigma)$ & $44 \leq \mathrm{x}<67$ & 53 & $100 \%$ & Sedang \\
$(\mu+1,0 \sigma) \leq \mathrm{x}$ & $68 \leq \mathrm{x}$ & 0 & $0 \%$ & Tinggi \\
\hline Total & & 53 & $100 \%$ \\
\hline
\end{tabular}

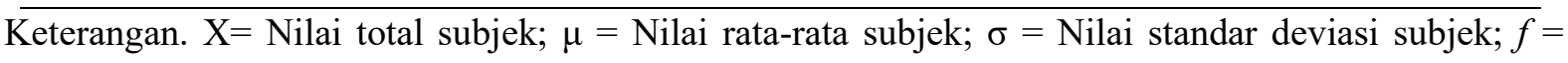
Frekuensi.

Data pada tabel 4 menunjukkan bahwa terdapat $0(0 \%)$ subjek yang memiliki competitive anxiety rendah,53 (100\%) subjek yang memiliki tingkat competitive anxiety sedang, dan $0(0 \%)$ subjek memiliki tingkat competitive anxiety tinggi.

Tabel 5.

Hasil Uji Hipotesis

\begin{tabular}{llll}
\hline Variabel & $r$ & $r^{2}$ & Keterangan \\
\hline $\begin{array}{l}\text { Mental Toughness } \\
\text { Competitive Anxiety }\end{array}$ & $0,729^{* *}$ & 0,531 & Signifikan \\
\hline
\end{tabular}

Keterangan. ${ }^{*} p<0,05$.

Hasil uji hipotesis menunjukkan bahwa terdapat pengaruh mental toughness terhadap competitive anxiety pada atlet karate UNM dengan nilai $p=0,000<0,05$, dan besarnya pengaruh $\left(r^{2}\right)$ mental toughness terhadap competitive anxiety adalah $r=0,531(53,1 \%)$. Kemudian untuk melihat arah koefisien korelasi menggunakan analisis korelasi product moment yang diperoleh sebesar 0,729. Arah penelitian yang didapatkan berbeda dari penelitian lainnya yang ditunjukkan dengan nilai koefisien korelasi $(r)$ bernilai positif, yaitu terdapat pengaruh positif mental toughness terhadap competitive anxiety pada atlet karate UNM, sehingga hipotesis ditolak.

Analisis lebih lanjut diterapkan dengan menggunakan uji $t$ independen yang bertujuan untuk menguji perbandingan mental toughness yang ditinjau berdasarkan jenis kelamin dan diperoleh nilai signifikansi sebesar 0,973 $(p>0,05)$ yang berarti tidak signifikan. Berdasarkan 
usia diperoleh hasil yang tidak signifikan $(p=0,249>0,05)$. Berdasarkan pengalaman bertanding juga melaporkan hasil tidak signifikan $(p=0,052>0,05)$. Sedangkan perbandingan competitive anxiety yang ditinjau berdasarkan jenis kelamin diperoleh nilai $p=0,933>0,05$, yang berarti tidak signifikan. Berdasarkan usia juga diperoleh hasil yang tidak signifikan $(0,919$ $>0,05)$. Namun, jika berdasarkan pada pengalaman bertanding menunjukkan hasil yang signifikan $(p=0,033<0,05)$.

\section{Pembahasan}

Pengujian hipotesis menggunakan analisis regresi linear sederhana dan korelasi product moment dengan bantuan aplikasi SPSS 22.00 dan STATCAL 1.0. Hasil uji hipotesis menunjukkan bahwa mental toughness berpengaruh positif terhadap competitive anxiety pada atlet karate $(r=0,729 ; p=0,000)$. Hasil tersebut juga menunjukkan bahwa terdapat arah positif pengaruh mental toughness terhadap competitive anxiety pada atlet karate UNM.

Hasil yang didapatkan penelitian ini berbeda dengan literatur yang telah dikemukakan sebelumnya yang menunjukkan bahwa mental toughness berpengaruh secara signifikan dan positif terhadap competitive anxiety pada atlet. Sehingga ketika mental toughness meningkat maka competitive anxiety menjadi meningkat. Peneliti menganggap bahwa ada faktor yang mempengaruhi mental toughness sehingga tidak berpengaruh negatif terhadap competitive anxiety pada atlet. Faktor yang dimaksud oleh peneliti yaitu pengalaman bertanding. Atlet yang memiliki pengalaman bertanding yang tinggi dapat mempengaruhi respon kecemasan atlet dalam menghadapi pertandingan. Kemampuan untuk mengendalikan kecemasan merupakan faktor yang sangat penting, yang harus dimiliki oleh atlet untuk menghasilkan suatu penampilan terbaik. Kemampuan untuk mengendalikan kecemasan didapatkan dari pengalaman-pengalaman atlet dalam menghadapi pertandingan. Atlet yang telah berpengalaman memiliki kemampuan kontrol yang baik dalam mengendalikan gejala-gejala kecemasan dibandingkan dengan atlet pemula, sehingga atlet bisa mencapai penampilan terbaik. Kemudian atlet yang sudah berpengalaman akan merasakan kecemasan hanya pada sebelum bertanding dibandingkan dengan atlet yang belum berpengalaman. Pero, Minganti, Pesce, Capranica, dan Piacentini (2013) mengemukakan bahwa salah satu komponen ketangguhan mental yaitu pengalaman bertanding. Atlet yang memiliki pengalaman bertanding akan lebih percaya diri dan menunjukkan tingkat kecemasan yang lebih rendah dari kecemasan bertanding. 
Temuan penelitian dari Hardiyono (2020) menemukan bahwa faktor pengalaman bertanding mempengaruhi kecemasan atlet dalam menghadapi pertandingan dengan sumbangsih sebesar $2.83 \%$, sehingga atlet mampu menampilkan performa terbaik. Kecemasan bertanding pada atlet silat dalam penelitian Raynadi, dkk. (2017) sebagian besar termasuk dalam kategori sedang yaitu sebanyak 21 atlet (70\%) dan kategori rendah yaitu sebanyak 9 atlet (30\%). Hasil penelitian tersebut membuktikan bahwa atlet yang berprestasi dan sudah berpengalaman memiliki tingkat kecemasan yang rendah. Nayek dan Chatterjee (2013) menambahkan bahwa atlet dengan tingkat kejuaraan tinggi lebih berpengalaman dan memiliki kemampuan penyesuaian terhadap lingkungan dan situasi sebelum kompetisi. Ia lebih mampu mengendalikan emosi dan kecemasannya. Selain itu, Athan dan Sampson (2013) menambahkan tingkat keterampilan, tingkat kegugahan dalam aktivitas keseharian dan pengalaman merupakan faktor yang mempengaruhi munculnya kecemasan bertanding.

Hasil uji hipotesis juga menunjukkan bahwa pengaruh mental toughness terhadap competitive anxiety sebesar 0,531 dilihat dari nilai $R$-Square, yang berarti bahwa memiliki pengaruh sebesar 53,1\%. Hasil ini membuktikan bahwa ketangguhan mental merupakan salah satu faktor yang dapat memprediksi kecemasan bertanding pada atlet karate. Sementara $46,83 \%$ sumbangan lainnya diduga dipengaruhi oleh konstrak lain yang tidak diukur dalam studi ini seperti pengalaman bertanding, efikasi diri, kondisi fisik, dan kontrol diri merupakan faktor yang dapat memberikan efek terhadap kecemasan bertanding. Jarvis (2006) mengemukakan bahwa terdapat dua faktor yang dapat memberikan pengaruh terhadap kecemasan bertanding pada atlet, yaitu faktor individu dan situasional. Faktor individu diartikan sebagai faktor yang berasal dari dalam diri atlet yang meliputi harga diri, kecemasan bawaan, perhatian terhadap performa, kondisi fisik, dan efikasi diri. Faktor situasional dapat diartikan sebagai faktor yang muncul karena lingkungan pertandingan seperti perubahan strategi permainan, adanya harapan dan tuntutan individu lain terhadap dirinya, ambiguitas dalam pertandingan, dan karakteristik pertandingan. Jarvis (2006) juga mengemukakan bahwa terdapat faktor yang dapat menimbulkan kecemasan bertanding yang berkaitan erat terhadap komponen pembentuk ketangguhan mental, seperti control yang berkaitan dengan harapan dan tuntutan individu lain terhadap dirinya, dan terjadinya ketidakjelasan dalam suatu kompetisi, confidence yang berkaitan dengan efikasi diri dan harga diri, serta commitment dan challenge yang berhubungan dengan faktor situasional dalam menghadapi lawan misalnya, perubahan strategi permainan, dan karakteristik pertandingan. 
Namun, dalam studi ini peneliti menemukan bahwa faktor lain yang mempengaruhi kecemasan bertanding yaitu frekuensi pengalaman dalam bertanding. Atlet yang memiliki dengan pengalaman bertanding yang tinggi maka dapat menurunkan competitive anxiety pada atlet. Meskipun mental toughness yang dimiliki oleh atlet berada pada tingkat yang tinggi, namun belum tentu mampu menurunkan kecemasan atlet pada saat bertanding. Hal ini seperti yang didapatkan dalam penelitian ini dengan adanya pengaruh positif, sehingga dapat dikatakan bahwa pengalaman bertanding menjadi faktor yang menyertai mental toughness untuk mengatasi kecemasan yang dialami oleh atlet. Oleh karena itu, peneliti menganggap faktor pengalaman bertanding ini dapat menjadi mediasi antara pengaruh mental toughness terhadap competitive anxiety pada atlet, sehingga perlu dilakukan penelitian yang lebih lanjut dalam mengungkap hal ini.

Kelemahan dari penelitian ini yaitu subjek yang dilibatkan dalam jumlah yang masih sedikit dan populasi yang ditentukan olah peneliti masih dalam skala yang kecil yaitu hanya di satu perguruan sehingga hasil penelitian ini tidak dapat digeneralisasikan dalam cakupan yang luas. Kemudian dalam penelitian ini, peneliti hanya ingin melihat pengaruh antara kedua variabel tidak mempertimbangkan variabel lainnya yang juga dapat memberikan pengaruh terhadap competitive anxiety, dan juga tidak sama sekali membahas mengenai cara atau prosedur pelatihan yang dapat mengurangi competitive anxiety atau meningkatkan mental toughness pada atlet sebagai salah satu solusi yang tepat.

\section{SIMPULAN}

Kesimpulan dari hasil penelitian ini yaitu terdapat pengaruh positif antara mental toughness terhadap competitive anxiety, mental toughness yang tinggi dapat membuat atlet tetap rileks dan menurunkan kecemasan pada atlet karate BKMF Fakultas Ilmu Keolahragaan Universitas Negeri Makassar.

Dari temuan penelitian ini, peneliti memiliki saran terhadap atlet, pelatih dalam bidang olahraga, dan peneliti selanjutnya. Atlet disarankan untuk menumbuhkan serta mempertahankan mental toughness agar dapat bertanding dalam kondisi yang benar-benar siap serta mengeluarkan performa terbaiknya sehingga mengurangi perilaku competitive anxiety yang akan muncul. Pelatih dalam bagian olahraga disarankan untuk memberikan dukungan dan memfasilitasi bagi setiap atlet seperti memberikan pembinaan sebagai upaya untuk menghasilkan kualitas mental toughness dan mengetahui gejala-gejala yang dapat menyebabkan atlet mengalami competitive anxiety sehingga dapat mengurangi perilaku cemas 
dan tetap fokus pada saat bertanding. Peneliti selanjutnya juga disarankan untuk melibatkan sampel dengan jumlah yang banyak dengan permasalahan yang sama yaitu kecemasan bertanding. Bagi peneliti yang ingin melakukan penelitian yang berbeda disarankan untuk melakukan pelatihan yang dapat mengurangi competitive anxiety atau meningkatkan mental toughness menggunakan metode eksperimen pada atlet dengan kategori olahraga yang lain.

\section{DAFTAR PUSTAKA}

Algani, P. W., Yuniardi, M. S., \& Masturah, A. N. (2018). Mental toughness dan competitive anxiety pada atlet bola voli. Jurnal Ilmiah Psikologi Terapan, 6(1), 93-101.

Athan, A.N., \& Sampson, U.I. (2013). Coping with pre-competitive anxiety in sports competition. European Journal of Natural and Applied Sciences, 1(1), 1-9.

Azwar, S. (2010). Metode penelitian. Yogyakarta: Pustaka Pelajar.

Gucciardi, D. F., Gordon, S., \& Dimmock, J. A. (2008). Towards an understanding of mental toughness in Australian Football. Journal of Applied Sport Psychology, 20(3), 261-281.

Hardiyono, B. (2020). Tingkat kecemasan sebelum bertanding dan percaya diri pada saat bertanding atlet Pelatda Pengprov FPTI Sumatera Selatan. Kinestetik: Jurnal Ilmiah Pendidikan Jasmani, 4(1), 47-54.

Jarvis, M. (2006). Sport psychology a student's handbook. New York: Routledge.

Nayek, B., \& Chatterjee, K. (2013).Comparative study on pre-competitive anxiety between national and state-level women athletes. Journal of Sports and Physical Education, 1(2), $33-36$.

Nugroho, S. W. (2012). Statistik pemuda indonesia. Jakarta: Badan Pusat Statistik.

Pero, R. D., Minganti, C., Pesce, C., Capranica, L., \& Piacentini, M. F. (2013). The relationships between pre-competition anxiety, self-efficacy, and fear of injury in elite team gym athletes. Kinesiology, 45(1), 63-72.

Raynadi, F. B., Rachmah, D. N., \& Akbar, S. N. (2017). Hubungan ketangguhan mental dengan kecemasan bertanding pada atlet pencak silat di Banjar baru. Jurnal Ecopsy, 3(3),149154.

Smith, R. E., Smoll, F. L., \& Schutz, R. W. (1990). Measurement and correlates of sportspecificcognitive and somatic trait anxiety: The sportanxiety scale. Anxiety Research,2(4), 263-280.

Sugiyono. (2011). Statistika untuk penelitian. Bandung: Alfabeta. 